\title{
Feline gastrointestinal parasitism in Greece: emergent zoonotic species and associated risk factors
}

Isaia Symeonidou', Athanasios I. Gelasakis², Konstantinos Arsenopoulos', Athanasios Angelou', Frederic Beugnet ${ }^{3}$ and Elias Papadopoulos ${ }^{1 *}$

\begin{abstract}
Background: Feline gastrointestinal parasitism constitutes an issue of concern for veterinarians since parasites are widespread and affect animals' health and welfare. Furthermore, some of these pathogens have zoonotic potential. To provide detailed data on the current epizootiology of feline endoparasitism, a multicentric survey was conducted during 2016.
\end{abstract}

Methods: Faeces from 1150 cats were collected from all regions of Greece and examined by sedimentation and flotation techniques. Possible risk factors including gender, age, ownership status, living conditions and co-infections with other parasites were assessed using binary regression models for each one of the most prevalent parasites.

Results: The overall gastrointestinal parasite prevalence in cats was 50.7\%. The study population consisted of cats of both sexes, different age groups, ownership status and living conditions. A total of 10 gastrointestinal parasitic species were detected and up to 5 different parasites were isolated in the same faecal sample. The most frequently identified parasites were Toxocara cati $(n=278 ; 24.2 \%)$, followed by Cystoisospora spp. $(n=189 ; 16.4 \%)$, Ancylostomatidae $(n=186$; 16.2\%), Aelurostrongylus abstrusus $(n=40 ; 3.5 \%)$, Giardia spp. $(n=26 ; 2.3 \%)$, Joyeuxiella pasqualei $(n=14 ; 1.2 \%)$, Capillaria aerophila $(n=8 ; 0.7 \%)$, Dipylidium caninum $(n=3 ; 0.2 \%)$, Toxascaris leonina $(n=2 ; 0.1 \%)$ and Troglostrongylus brevior $(n=2 ; 0.1 \%)$. The occurrence of co-infections was $11.6 \%$. Concerning risk factors, the likelihood of $T$. cati infection was higher for female cats living outdoors and for cats being infected with Cystoisospora spp. In the same frame, young, stray, male and free of A. abstrusus cats were more likely to be infected with Cystoisospora spp. Correspondingly, stray, infected with Giardia spp. but free of Cystoisospora spp. cats were more likely to be infected with Ancylostomatidae. Regarding A. abstrusus infection, a higher probability was reported for cats living outdoors and for cats free of Cystoisospora spp., while Giardia spp. infections were more common in young and co-infected with Ancylostomatidae animals.

Conclusions: The prevalence of parasitized cats in Greece was high and thus consideration should be paid to control the risk factors, to implement targeted preventive antiparasitic treatments and educate cat owners on the value of prevention for the health and welfare of their cats.

Keywords: Cats, Gastrointestinal parasites, Greece, Risk factors, Zoonotic potential

\footnotetext{
* Correspondence: eliaspap@vet.auth.gr

${ }^{1}$ Laboratory of Parasitology and Parasitic Diseases, School of Veterinary

Medicine, Faculty of Health Sciences, Aristotle University of Thessaloniki, PO

Box: 393, GR 54124 Thessaloniki, Greece

Full list of author information is available at the end of the article
} 


\section{Background}

Cats are common pets and have become part of human families offering companionship [1]. Cats may harbour numerous endoparasites, including protozoa, cestodes, trematodes and nematodes [2]. Among parasites, the gastrointestinal ones may affect cats' well-being, causing clinical signs like listlessness, dull haircoat, vomiting, diarrhoea, poor growth rate, anaemia and sometimes even death, especially in kittens [3, 4]. Additionally, parasitized cats tend to be more susceptible to viral and bacterial infections, as well as to other diseases, thus their health and welfare status are impaired [5]. Furthermore, some feline parasites, such as Toxocara cati and hookworms may cause diseases, such as visceral and ocular larva migrans and others, including Cryptosporidium spp., Giardia spp., Echinococcus multilocularis and Dipylidium caninum have the potential to infect humans, either via direct contact or via exposure to contaminated environment [6-9].

Constant monitoring of the active regional prevalence of feline gastrointestinal parasitism and assessing of the specific risk factors involved can provide valuable clues for effective surveillance and prevention [6]. For veterinary practitioners it is important to estimate the changes of their patient to be parasitized in order to implement targeted parasite control schemes. Another aspect of prime importance is the possible public health implication and the appropriate education for applying efficient preventive measures, and thus reducing the zoonotic potential of pet infections [10].

Many studies have investigated the occurrence of feline gastrointestinal parasitism throughout Europe. As reported in two recent multicentric surveys in Europe, these pathogens affect from $30.8 \%$ up to $35.1 \%$ of owned cats $[11,12]$. Depending upon the parasite species, the study population and the diagnostic procedure used, the prevalence estimates vary widely among different countries [12]. It should be emphasized that for stray cat populations the infection rate reaches even up to $100 \%$ as a result of inadequate control of parasites and access to intermediate hosts, as indicated by Millan \& Casanova [13]. In Greece, there are no comprehensive, large-scale studies regarding the distribution of feline gastrointestinal parasites. All previous studies have been carried out on a small animal population that originated from geographically limited areas of the country, and thus knowledge is fragmented and completely absent for several parts of the country [12, 14-16]. Since Greece is one of the world's most popular tourist destinations, the continual flow of pets along with the abundant presence of stray cats may have major epidemiological implications.

The objective of this cross-sectional study was to evaluate the current prevalence of feline gastrointestinal parasites in Greece from all regions of the country. Effort was put to assess the emergence of zoonotic cat parasites and to demonstrate their potential interactions. Moreover, this study aimed to designate the risk factors in view of creating a clearer picture of the feline gastrointestinal parasitism in Greece.

\section{Methods}

\section{Study area and cat population}

A total of 1150 faecal samples were collected between January 2016 and November 2016 from clinically healthy cats across Greece, both from the mainland and islands (Fig. 1). Information regarding gender, age, ownership status and living conditions were recorded for each animal sampled. The gender of cats was almost evenly distributed with $553(48.1 \%)$ males and 597 (51.9\%) females. The majority of cats were over 6 months old ( $n=1066$ cats; $92.7 \%)$, while young animals ( $<6$ months old) represented $7.3 \%$ of the studied population ( $n=84$ cats). Regarding ownership status, samples were collected from owned $(n=560 ; 48.7 \%)$ and from stray cats $(n=590 ; 51.3 \%)$. Regarding lifestyle, most of the cats were living outdoors $(n=926$ cats; $80.5 \%)$ rather than strictly indoors ( $n=224$ cats; $19.5 \%)$. None of the examined animals received any anthelmintic treatment minimum 3 months prior to inclusion.

\section{Faecal sample collection and coprological methods used}

From each individual cat, a faecal sample was collected either at the time of consultation or within $24 \mathrm{~h}$ from the cat litter box (when more than one cat per household, animals were isolated in order to accurately identify the sample). Samples were placed individually in plastic containers, labeled with consecutive numbers, stored at $2-6{ }^{\circ} \mathrm{C}$, transferred to the Laboratory of Parasitology and Parasitic Diseases of the School of Veterinary Medicine in Thessaloniki and processed within $48 \mathrm{~h}$.

Initially, each sample was macroscopically examined to detect the possible presence of cestode proglottids and/or adult nematodes. Thereafter, each sample was subjected to a microscopic analysis with a sedimentation and a flotation $\left(\mathrm{ZnSO}_{4} 33.2 \%\right.$, specific weight 1.3) technique [17]. Identification of parasites was based on morphological and morphometric features $[18,19]$. A cat was considered infected if at least one parasitic element (cyst, oocyst, egg, proglottid or larva) was observed.

\section{Data handling: statistical analyses}

Data were recorded in a Microsoft Excel spreadsheet, appropriately designed for the subsequent analyses (Additional file 1: Table S1, Table S2). Prevalence values were calculated as the proportion of positive animals to the total number of examined animals, whereas the relative prevalence of each parasite species was calculated 


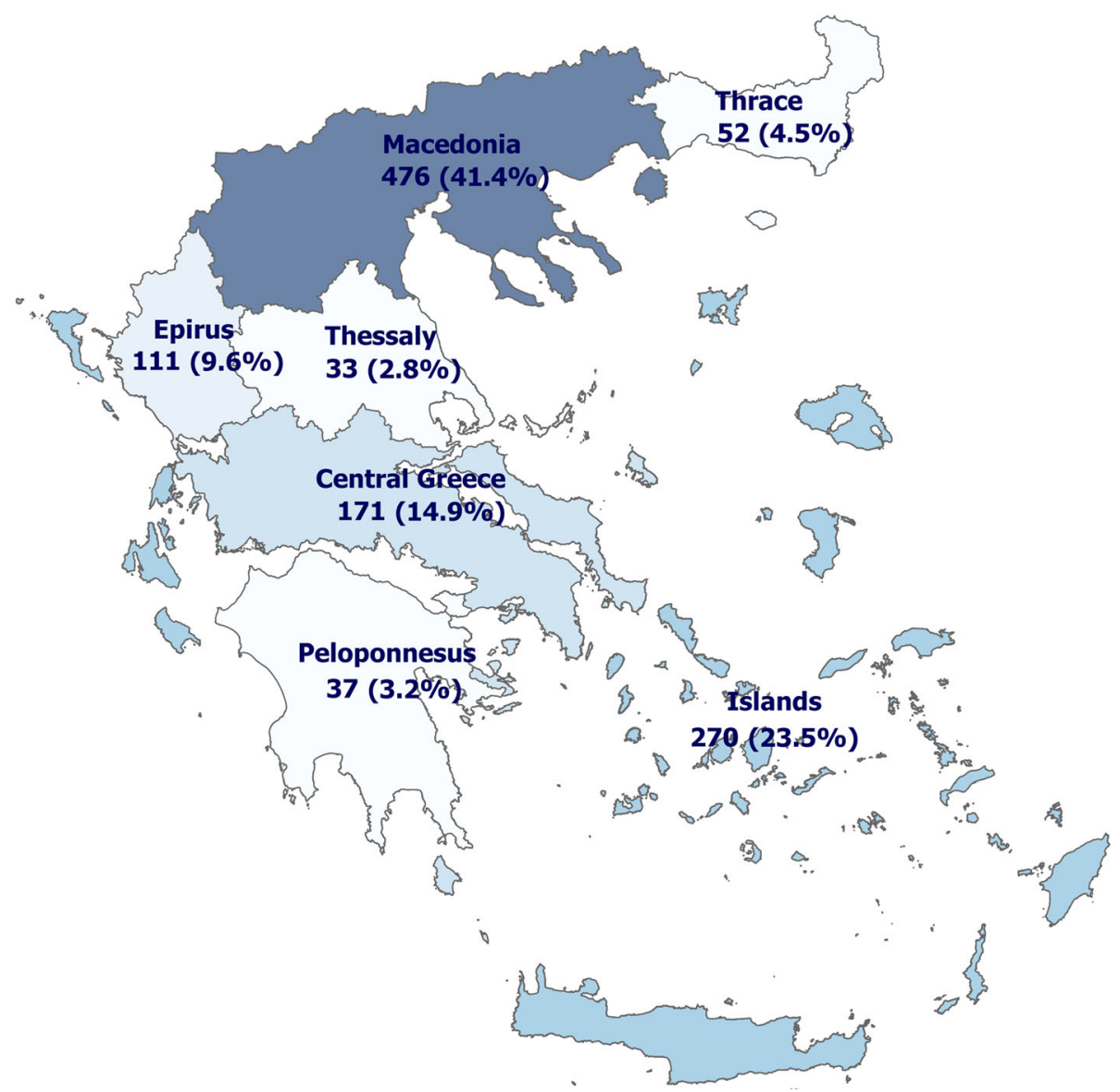

Fig. 1 Map displaying the numbers and percentages of feline faecal samples collected per regions of Greece

as the proportion of cats infected with a given parasite species within the total number of positive results. The 95\% confidence intervals (CI) of the prevalence values were estimated using the Wilson score interval method. Mean species richness was calculated for gender, age, ownership status and living conditions groups using the Menhinick's index $\left(\mathrm{D}=\frac{s}{\sqrt{N}}\right)$, where $s$ is the number of parasite genera and $N$ is the total number of cats in the sample.

Initially, five binary logistic regression models were used in order to assess the effects of possible risk factors (gender, age, ownership status, lifestyle, and co-infection with other parasites) and the likelihood that a cat is infected with the most prevalent parasites, namely, $T$. cati, Cystoisospora (syn. Isospora) spp., Ancylostomatidae (Ancylostoma/Uncinaria spp.), Aelurostrongylus abstrusus and Giardia spp., as described in Model 1:

$$
\begin{aligned}
Y_{P}= & \alpha+\beta_{1} X_{1}+\beta_{2} X_{2}+\beta_{3} X_{3}+\beta_{4} X_{4}+\beta_{5} X_{5}+\beta_{6} X_{6} \\
& +\beta_{7} X_{7}+\beta_{8} X_{8}+\beta_{9} X_{9}(\text { Model 1) }
\end{aligned}
$$

where, $Y_{P}$ is the probability of a cat being infected with the most prevalent parasites ( $T$. cati, Cystoisospora spp., Ancylostomatidae, A. abstrusus and Giardia spp.), $\beta_{1}$ to $\beta_{9}$, the regression coefficients of gender $\left(X_{2}, 0=\right.$ male, $1=$ female), age ( $X_{3}, 0=\leq 6$ months, $1=>6$ months $)$, ownership status $\left(\mathrm{X}_{4}, 0=\right.$ with owner, $1=$ stray), lifestyle ( $\mathrm{X}_{1}, 0=$ outdoors, 1 = indoors), and T. cati, Cystoisospora spp., Ancylostomatidae, A. abstrusus and Giardia spp. infection status $\left(\mathrm{X}_{5}\right.$ to $\mathrm{X}_{9}$, respectively, with 0 indicating the absence and 1 the presence of infection).

A stepwise procedure was followed and only predictors that had a significant effect $(P<0.05)$ or tended to have a significant effect $(P<0.10)$ on each individual parasitic infection were used for the final models.

Based on this, the likelihood of (i) T. cati, (ii) Cystoisospora spp., (iii) Ancylostomatidae, (iv) A. abstrusus and (v) Giardia spp. infection was estimated using as predictors the regression coefficients of (i) lifestyle, gender and Cystoisospora spp. infection status $\left(\beta_{1}, \beta_{2}\right.$ and $\beta_{6}$, respectively), (ii) gender, age, ownership status and $A$. abstrusus infection status $\left(\beta_{2}, \beta_{3}, \beta_{4}\right.$ and $\beta_{8}$, respectively), (iii) ownership status, Cystoisospora spp. and Giardia spp. infection status $\left(\beta_{4}, \beta_{6}\right.$ 
and $\beta_{9}$, respectively), (iv) lifestyle and Cystoisospora spp. infection status $\left(\beta_{1}\right.$, and $\beta_{6}$, respectively) and (v) age and Ancylostomatidae infection status $\left(\beta_{3}\right.$, and $\beta_{7}$, respectively).

Statistical significance of individual predictors was tested using the Wald $\chi^{2}$ statistic of their regression coefficients $(\beta \mathrm{s})$. The Hosmer-Lemeshow (H-L) test, as well as the Cox and Snell $R^{2}$ and Nagelkerke $R^{2}$ indices were used to assess the goodness-of-fit for each individual model. The ability of the models to correctly predict parasitic infections was assessed by calculating the receiver operating characteristic (ROC) and estimating the areas underneath them (AUC, c-statistic).

The models were validated using an 80-20 crossvalidation analysis with the training sample (the sample used to build the model) including $80 \%$ of the studied cases and the holdout sample including the remaining $20 \%$; during validation of the model the holdout sample was classified using the coefficients, derived by the model built using the training sample. The classification accuracy of the holdout sample was used to estimate the effectiveness of the model performance for the studied population of cats; a classification accuracy rate within $10 \%$ of the training sample was considered to evidence the utility of the model. Moreover, the model was considered efficient when the significance of the predictors' coefficients in the full-data model matched with the coefficients' significance in the training sample model.

\section{Results}

\section{Epizootiology of gastrointestinal parasites in the studied cat population}

Overall, $50.7 \%(583 / 1150)$ of the sampled cats were detected to excrete at least one parasitic element. Among examined animals ( $n=1150$ cats), 449 cats $(39.0 \%, 95 \%$ CI: 36.3-42.0\%) were harbouring only one parasitic genus, while 107 (9.3\%, 95\% CI: 7.8-11.1\%), 25 (2.2\%, 95\% CI: $1.5-3.2 \%)$ and $2(0.18 \%, 95 \% \mathrm{CI}: 0-0.01 \%)$ cats were found to be infected with species of two, three and more than four different parasite genera, respectively. Overall, eight gastrointestinal and two pulmonary parasite species were detected. Toxocara cati was the most prevalent parasite in the studied population ( $n=278$ cats; $24.2 \%$ ), followed by Cystoisospora spp. ( $n=189$ cats; $16.4 \%)$, Ancylostomatidae ( $n=186$ cats; $16.2 \%), A$. abstrusus ( $n=40$ cats; $3.5 \%$ ), Giardia spp. ( $n=26$ cats; $2.3 \%)$, Joyeuxiella pasqualei ( $n=14$ cats; $1.2 \%)$, Capillaria aerophila (syn. Eucoleus aerophilus) ( $n=8$ cats; $0.7 \%)$, D. caninum ( $n=3$ cats; $0.2 \%)$, Toxascaris leonina and Troglostrongylus brevior $(n=2$ cats each; 0.1\%) (Additional file 1: Table S1, Table S2). The prevalence estimates of the detected parasites are summarized in Table 1. Menhinick's index (D) was 0.54 for young cats and 0.31 for the adult cats. No remarkable
Table 1 Prevalence of gastrointestinal and respiratory parasites in the studied cats $(n=1150)$

\begin{tabular}{llll}
\hline Parasite & $\begin{array}{l}\text { No. of positive } \\
\text { cats }\end{array}$ & $\begin{array}{l}\text { Prevalence } \\
(\%)\end{array}$ & $\begin{array}{l}95 \% \mathrm{Cl} \\
(\%)\end{array}$ \\
\hline Toxocara cati & 278 & 24.2 & $21.8-26.7$ \\
Cystoisospora spp. & 189 & 16.4 & $14.4-18.7$ \\
Ancylostomatidae & 186 & 16.2 & $14.2-18.4$ \\
Aelurostrongylus abstrusus & 40 & 3.5 & $2.6-4.7$ \\
Giardia spp. & 26 & 2.3 & $1.6-3.3$ \\
Joyeuxiella pasqualei & 14 & 1.2 & $0.7-2.0$ \\
Capillaria aerophila & 8 & 0.7 & $0.4-1.4$ \\
Dipylidium caninum & 3 & 0.2 & $0-0.8$ \\
Toxascaris leonina & 2 & 0.1 & $0-0.6$ \\
Troglostrongylus brevior & 2 & 0.1 & $0-0.6$ \\
Total (with at least one & 583 & 50.7 & $47.8-53.6$ \\
parasite) & & &
\end{tabular}

differences regarding $\mathrm{D}$ were observed between males $v s$ females and owned $v s$ stray cats (in both cases, 0.38 vs 0.41 ). The range of $\mathrm{D}$ values observed in the studied regions was from 0.41 to 0.69 . More details, including the number, prevalence (\%) of infected (per parasite taxon) cats and the Menhinick's index in all sampled regions of Greece are shown in Table 2 (Additional file 1: Table S3).

Effects of risk factors on parasitic infections with $T$. cati, Cystoisospora spp., Ancylostomatidae, A. abstrusus and Giardia spp.

The effects of the studied risk factors forced into the regression models (gender, age, ownership status, living conditions, co-infection with other parasites) and the cross-validation of the models for the five parasite taxa (Toxocara, Cystoisospora, Ancylostomatidae, Aelurostrongylus and Giardia) are presented below (Tables 3, 4, 5, 6, 7 and 8).

\section{Toxocara cati}

Table 4 presents the risk factors used for the $T$. cati model and their effects on $T$. cati infection status. The likelihood of $T$. cati infection was higher $(B=0.98, d f=1$, $P<0.0001)$ for cats living outdoors in comparison to those living indoors (c.2.7 times, 95\% CI: 1.7-4.1), although no significant difference was noted between owned and stray cats. Similarly, a 1.3-fold higher (95\% CI: $1-1.7)$ probability for $T$. cati infection was recorded for female cats, which, though, was not statistically significant $(B=-0.25, d f=1, P=0.081)$. Regarding co-infections, cats infected with Cystoisospora spp. were 1.4 times (95\% CI: 1-1.9) more likely to be infected with $T$. cati when compared to non-infected ones $(B=-0.31$, $d f=1, P=0.086)$. The model provided a good fit to the data with the H-L test being insignificant $\left(\chi^{2}=1.85\right.$, 
Table 2 Number and prevalence (\%) of infected (per parasite taxon) cats and mean species richness (Menhinick's index) in all sampled regions of Greece

\begin{tabular}{|c|c|c|c|c|c|c|c|c|c|c|c|}
\hline Region (no. of examined cats) & $T C$ & Cystois. spp. & Ancyl. & $\mathrm{Aa}$ & Giar. spp. & $J p$ & $\mathrm{Ca}$ & $D C$ & $\mathrm{TI}$ & $T b$ & $\mathrm{D}$ \\
\hline Macedonia $(n=476)$ & $128(26.9)$ & $99(20.8)$ & $12(2.5)$ & $17(3.6)$ & $2(0.4)$ & $8(1.7)$ & $2(0.4)$ & $2(0.4)$ & $1(0.2)$ & $0(0)$ & 0. \\
\hline Islands $(n=270)$ & $68(25.2)$ & $33(12.2)$ & $152(56.3)$ & $11(4.1)$ & $16(5.9)$ & $0(0)$ & $5(1.9)$ & $0(0)$ & $0(0)$ & $1(0.4)$ & \\
\hline Central Greece $(n=171)$ & $39(22.8)$ & $24(14.0)$ & $14(8.2)$ & $3(1.8)$ & $0(0)$ & $4(2.3)$ & $0(0)$ & $0(0)$ & $1(0.6)$ & $1(0.6)$ & \\
\hline Epirus $(n=111)$ & $24(21.6)$ & $13(11.7)$ & $5(4.5)$ & $6(5.4)$ & $3(2.7)$ & $1(0.9)$ & $1(0.9)$ & $0(0)$ & $0(0)$ & $0(0)$ & \\
\hline Thrace $(n=52)$ & $13(25.0)$ & $5(9.6)$ & $3(5.8)$ & $1(1.9)$ & $0(0)$ & $1(1.9)$ & $0(0.0)$ & $0(0)$ & $0(0)$ & $0(0)$ & \\
\hline Peloponnesus $(n=37)$ & $5(13.5)$ & $4(10.8)$ & $0(0)$ & $2(5.4)$ & $0(0)$ & $0(0)$ & $0(0)$ & $0(0)$ & $0(0)$ & $0(0)$ & \\
\hline Thessaly $(n=33)$ & $1(3.0)$ & $11(33.3)$ & $0(0)$ & $0(0)$ & $5(15.2)$ & $0(0)$ & $0(0)$ & $0(0)$ & $0(0)$ & $0(0)$ & 0. \\
\hline
\end{tabular}

Abbreviations: Tc Toxocara cati, Cystois. spp. Cystoisospora spp., Ancyl. Ancylostomatidae, Aa Aelurostrongylus abstrusus, Giar. spp. Giardia spp., Jp Joyeuxiella pasqualei, Ca Capillaria aerophila, Dc Dipylidium caninum, TI Toxascaris leonina, Tb Troglostrongylus brevior, D Menhinick's species richness index

$d f=5, P=0.869)$. Moreover, according to the Omnibus test of coefficients the model had a significant predictive value for $T$. cati infection $\left(\chi^{2}=30.509, d f=3, P<0.0001\right)$ with a c-statistic equal to $0.60(P<0.001)$. Cox and Snell $R^{2}$-value, and Nagelkerke $R^{2}$-value were 0.026 and 0.039 , respectively.

\section{Cystoisospora spp.}

Young cats were 3.2 times (95\% CI: 1.9-5.3) more likely to be infected with Cystoisospora spp. when compared to adult cats $(B=1.16, d f=1, P<0.0001)$. Likewise, the probability of Cystoisospora spp. infection for stray cats was significantly higher $(B=-0.77, d f=1, P<0.0001)$ in comparison to owned cats (c.2.2 times, 95\% CI: 1.6-3.0). In addition, the likelihood of Cystoisospora spp. infection was found 1.4 times (95\% CI: 1.0-1.9) higher for male cats $(B=0.33, d f=1, P=0.044)$. Noticeably, animals free of Aelurostrongylus abstrusus were c.4 times (95\% CI: 0.9-16.6) more likely to be infected with Cystoisospora spp. $(B=1.37, d f=1, P=0.062)$. Table 5 summarizes the effects of the predictors used in the Cystoisospora spp. model. The $\mathrm{H}-\mathrm{L}$ test was statistically insignificant indicating that the model fits the data well $\left(\chi^{2}=0.825, d f=5\right.$, $P=0.975)$. Moreover, according to the Omnibus test of coefficients, the model was predictive of Cystoisospora spp. infection $\left(X^{2}=45.777, d f=4, P<0.0001\right)$ with a c-statistic

Table 3 Accuracy rate of the full dataset, the training (80\%) and the holdout sample (20\%) of Toxocara cati, Cystoisospora spp., Ancylostomatidae, Aelurostrongylus abstrusus and Giardia spp. models

\begin{tabular}{|c|c|c|c|c|c|c|c|c|c|c|}
\hline \multirow[t]{4}{*}{ Observed cases } & & \multicolumn{3}{|c|}{ Predicted cases for the full-data model } & \multicolumn{6}{|c|}{ Predicted cases for the split-sample validation model } \\
\hline & & \multirow{2}{*}{\multicolumn{2}{|c|}{ Infection status $^{a}$}} & \multirow{3}{*}{$\begin{array}{l}\text { Percentage } \\
\text { correct }(\%)\end{array}$} & \multicolumn{3}{|c|}{ Selected cases } & \multicolumn{3}{|c|}{ Unselected cases } \\
\hline & & & & & \multicolumn{2}{|c|}{ Infection status $^{a}$} & \multirow[t]{2}{*}{$\%$ correct } & \multicolumn{2}{|c|}{ Infection status $^{a}$} & \multirow[t]{2}{*}{$\%$ correct } \\
\hline & & Uninfected & Infected & & Uninfected & Infected & & Uninfected & Infected & \\
\hline \multirow[t]{3}{*}{ Toxocara cati infection status } & Uninfected & 874 & 0 & 100 & 705 & 0 & 100 & 169 & 0 & 100 \\
\hline & Infected & 278 & 0 & 0 & 223 & 0 & 0 & 55 & 0 & 0 \\
\hline & Accuracy rate & & & 75.9 & & & 76.0 & & & 75.4 \\
\hline \multirow{3}{*}{$\begin{array}{l}\text { Cystoisospora spp. infection } \\
\text { status }\end{array}$} & Uninfected & 963 & 0 & 100 & 741 & 0 & 100 & 222 & 0 & 100 \\
\hline & Infected & 189 & 0 & 0 & 155 & 0 & 0 & 34 & 0 & 0 \\
\hline & Accuracy rate & & & 83.6 & & & 82.7 & & & 86.7 \\
\hline \multirow{3}{*}{$\begin{array}{l}\text { Ancylostomatidae infection } \\
\text { status }\end{array}$} & Uninfected & 961 & 5 & 99.5 & 766 & 2 & 99.7 & 197 & 1 & 99.5 \\
\hline & Infected & 173 & 13 & 7.0 & 134 & 9 & 6.3 & 40 & 3 & 7.0 \\
\hline & Accuracy rate & & & 84.5 & & & 85.1 & & & 83.0 \\
\hline \multirow{3}{*}{$\begin{array}{l}\text { Aelurostrongylus abstrusus } \\
\text { infection status }\end{array}$} & Uninfected & 1112 & 0 & 100 & 878 & 0 & 100 & 234 & 0 & 100 \\
\hline & Infected & 40 & 0 & 0 & 31 & 0 & 0 & 9 & 0 & 0 \\
\hline & Accuracy rate & & & 96.5 & & & 96.6 & & & 96.3 \\
\hline \multirow[t]{3}{*}{ Giardia spp. infection status } & Uninfected & 1126 & 0 & 100 & 907 & 0 & 100 & 219 & 0 & 100 \\
\hline & Infected & 26 & 0 & 0 & 18 & 0 & 0 & 8 & 0 & 0 \\
\hline & Accuracy rate & & & 97.7 & & & 98.1 & & & 96.5 \\
\hline
\end{tabular}

Infection status refers to Toxocara cati, Cystoisospora spp., Ancylostomatidae, Aelurostrongylus abstrusus and Giardia spp. predicted infection status in accordance to the observed infection status of the aforementioned parasite species 
Table 4 Regression coefficients of the predictors used in Toxocara cati model for the full dataset ( $f$ ) and the training sample (ts) used for the validation of the model

\begin{tabular}{|c|c|c|c|c|c|c|}
\hline & $B^{a}$ & SE & Wald & $P$ & Odds ratio & 95\% Cl for $\operatorname{Exp}(B)$ \\
\hline Living outdoors (f) & 0.98 & 0.219 & 19.78 & $<0.001$ & 2.651 & $1.725-4.074$ \\
\hline Living outdoors (ts) & 0.95 & 0.244 & 15.35 & $<0.001$ & 2.596 & $1.611-4.184$ \\
\hline Living indoors & Ref. & & & & & \\
\hline Male $(f)$ & -0.25 & 0.140 & 3.04 & 0.081 & 0.783 & $0.595-1.031$ \\
\hline Male (ts) & -0.35 & 0.157 & 4.95 & 0.026 & 0.705 & $0.518-0.959$ \\
\hline Female & Ref. & & & & & \\
\hline No Cystoisospora spp. infection (f) & -0.31 & 0.179 & 2.95 & 0.086 & 0.736 & $0.519-1.044$ \\
\hline No Cystoisospora spp. infection (ts) & -0.21 & 0.202 & 1.11 & 0.293 & 0.808 & $0.544-1.201$ \\
\hline Cystoisospora spp. infection & Ref. & & & & & \\
\hline Constant $(f)$ & -1.60 & 0.269 & 35.48 & $<0.001$ & 0.201 & \\
\hline Constant (ts) & -1.62 & 0.301 & 29.01 & $<0.001$ & 0.197 & \\
\hline
\end{tabular}

Abbreviations: SE standard error, $\mathrm{Cl}$ confidence interval, Ref. reference category

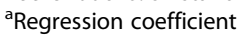

equal to $0.65(P<0.0001)$. Cox and Snell $R^{2}$-value and Nagelkerke $R^{2}$-value were 0.039 and 0.066 , respectively.

\section{Ancylostomatidae}

Stray cats were 8.8 times (95\% CI: 5.6-13.9) more likely to be infected with Ancylostomatidae when compared to owned cats $(B=-2.18, d f=1, P<0.0001)$. In the same context, cats infected with Giardia spp. were 5.1 times (95\% CI: 2.1-12.0) more likely to be parasitized with hookworms when compared to non-infected cats $(B=-1.62$, $d f=1, P=0.0003)$. Finally, Cystoisospora spp.-free cats were 1.8 times (95\% CI: 1.1-2.9) more likely to be infected with Ancylostomatidae $(B=0.59, d f=1, P=0.015)$.
Table 6 summarizes the effects of the predictors used in the Ancylostomatidae model. The $\mathrm{H}-\mathrm{L}$ test was statistically insignificant indicating that the model fits the data well $\left(\chi^{2}=2.094, d f=3, P=0.553\right)$. Moreover, according to the Omnibus test of coefficients the model was predictive of Cystoisospora spp. infection $\left(\chi^{2}=146.172, d f=3, P<0.0001\right)$ with a c-statistic equal to $0.74(P<0.0001)$. Cox and Snell $R^{2}$-value and Nagelkerke $R^{2}$-value were 0.119 and 0.203 , respectively.

\section{Aelurostrongylus abstrusus}

Table 7 shows the risk factors assessed in the A. abstrusus model. A 5.2 times (95\% CI: 1.2-21.7) higher probability

Table 5 Regression coefficients of the predictors used in Cystoisospora spp. model for the full dataset ( $\mathrm{f}$ ) and the training sample (ts) used for the validation of the model

\begin{tabular}{|c|c|c|c|c|c|c|}
\hline & $B^{a}$ & SE & Wald & $P$ & Odds ratio & $95 \% \mathrm{Cl}$ for $\operatorname{Exp}(B)$ \\
\hline$<6$ months (f) & 1.16 & 0.254 & 20.97 & $<0.001$ & 3.203 & $1.946-5.272$ \\
\hline$<6$ months (ts) & 1.27 & 0.277 & 20.91 & $<0.001$ & 3.546 & $0.797-1.311$ \\
\hline$>6$ months & Ref. & & & & & \\
\hline Owned cats (f) & -0.77 & 0.170 & 20.59 & $<0.001$ & 0.462 & $0.331-0.645$ \\
\hline Owned cats (ts) & -0.77 & 0.189 & 16.49 & $<0.001$ & 0.465 & $0.321-0.673$ \\
\hline Stray & Ref. & & & & & \\
\hline Male $(f)$ & 0.33 & 0.163 & 4.07 & 0.044 & 1.390 & $1.009-1.913$ \\
\hline Male (ts) & 0.13 & 0.181 & 0.50 & 0.479 & 1.137 & $0.797-1.620$ \\
\hline Female & Ref. & & & & & \\
\hline No Aelurostrongylus abstrusus infection ( $f$ ) & 1.37 & 0.735 & 3.47 & 0.062 & 3.930 & $0.931-16.587$ \\
\hline No Aelurostrongylus abstrusus infection (ts) & 1.15 & 0.746 & 2.36 & 0.125 & 3.144 & $0.729-13.560$ \\
\hline Aelurostrongylus abstrusus infection & Ref. & & & & & \\
\hline Constant $(f)$ & -2.92 & 0.736 & 15.72 & 0.001 & 0.054 & \\
\hline Constant (ts) & -2.54 & 0.745 & 11.66 & 0.001 & 0.079 & \\
\hline
\end{tabular}

Abbreviations: SE standard error, Cl confidence interval, Ref. reference category 
Table 6 Regression coefficients of the predictors used in Ancylostomatidae model for the full data set $(f)$ and the training sample (ts) used for the validation of the model

\begin{tabular}{|c|c|c|c|c|c|c|}
\hline & $B^{a}$ & SE & Wald & $P$ & Odds ratio & $95 \% \mathrm{Cl}$ for $\operatorname{Exp}(\mathrm{B})$ \\
\hline Owned cats (f) & -2.18 & 0.231 & 89.57 & $<0.001$ & 0.113 & $0.072-0.177$ \\
\hline Owned cats (ts) & -2.28 & 0.265 & 73.79 & $<0.001$ & 0.103 & $0.061-0.172$ \\
\hline Stray & Ref. & & & & & \\
\hline No Giardia spp. infection (f) & -1.62 & 0.446 & 13.16 & $<0.001$ & 0.198 & $0.083-0.475$ \\
\hline No Giardia spp. infection (ts) & -1.44 & 0.509 & 7.97 & 0.005 & 0.238 & $0.088-0.644$ \\
\hline Giardia spp. infection & Ref. & & & & & \\
\hline No Cystoisospora spp. infection ( $f$ ) & 0.59 & 0.242 & 5.89 & 0.015 & 1.800 & $1.120-2.894$ \\
\hline No Cystoisospora spp. infection (ts) & 0.68 & 0.281 & 5.88 & 0.015 & 1.978 & $1.139-3.433$ \\
\hline Cystoisospora spp. infection & Ref. & & & & & \\
\hline Constant (f) & 0.11 & 0.483 & 0.05 & 0.821 & 1.115 & \\
\hline Constant (ts) & -0.14 & 0.555 & 0.07 & 0.795 & 0.866 & \\
\hline
\end{tabular}

Abbreviations: SE standard error, $\mathrm{Cl}$ confidence interval, Ref. reference category

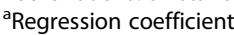

of $A$. abstrusus infection was recorded for cats living outdoors when compared to those living indoors $(B=1.65$, $d f=1, P=0.024)$. Analogously, cats free of Cystoisospora spp. were 4.3 times (95\% CI: $1.0-17.9$ ) more likely to be infected with $A$. abstrusus when compared to infected cats $(B=1.46, d f=1, P=0.046)$. The $\mathrm{H}-\mathrm{L}$ goodness-of-fit test in the $A$. abstrusus model indicated a good fit $\left(\chi^{2}=0.045\right.$, $d f=2, P=0.978)$. A significant predictive value for $A$. abstrusus infection was indicated by the Omnibus test of model coefficients $\left(\chi^{2}=13.432, d f=2, P=0.001\right)$ with ROC analysis showing a c-statistic equal to $0.63(P=0.006)$. Cox and Snell $R^{2}$-value and Nagelkerke $R^{2}$-value were 0.012 and 0.045 , respectively.

\section{Giardia spp.}

Table 8 shows the effect size of the risk factors used into Giardia spp. model. Young cats were 4.7 times (95\% CI: 1.4-15.7) more likely to be infected with Giardia spp. when compared to adult cats $(B=1.55, d f=1, P=0.011)$. In the same frame, co-infection with Ancylostomatidae was associated with a 7.2 times (95\% CI: 3.1-17.2) higher likelihood of Giardia spp. infection $(B=-1.98$, $d f=1, P<0.0001)$. According to the $\mathrm{H}-\mathrm{L}$ test, the Giardia spp. model fitted well the data $\left(\chi^{2}=0.000, d f=1\right.$, $P=1.000$ ). Also, the Omnibus test of model coefficients was significant and the model was predictive of Giardia spp. infection $\left(\chi^{2}=21.547, d f=2, P<0.0001\right)$ producing a c-statistic equal to $0.72(P=0.0001)$. In the same model, Cox and Snell $R^{2}$-value and Nagelkerke $R^{2}$-value were 0.019 and 0.095 , respectively.

\section{Discussion}

Feline gastrointestinal parasitism represents a topic of increasing interest in veterinary medicine. The aim of this extensive survey was to provide a detailed view of the epizootiology of feline gastrointestinal parasites in Greece. To the best of our knowledge, this is the first study in Greece to include such a large sample with a representative geographical distribution of the general cat population,

Table 7 Regression coefficients of the predictors used in Aelurostrongylus abstrusus model for the full data set ( $f$ ) and the training sample (ts) used for the validation of the model

\begin{tabular}{|c|c|c|c|c|c|c|}
\hline & $B^{a}$ & SE & Wald & $P$ & Odds ratio & $95 \% \mathrm{Cl}$ for $\operatorname{Exp}(\mathrm{B})$ \\
\hline Living outdoors (f) & 1.65 & 0.730 & 5.07 & 0.024 & 5.179 & $1.238-21.656$ \\
\hline Living outdoors (ts) & 1.37 & 0.737 & 3.47 & 0.062 & 3.949 & $0.932-16.736$ \\
\hline Living indoors & Ref. & & & & & \\
\hline No Cystoisospora spp. infection ( $f$ ) & 1.46 & 0.731 & 3.97 & 0.046 & 4.286 & $1.024-17.946$ \\
\hline No Cystoisospora spp. infection (ts) & 1.17 & 0.738 & 2.51 & 0.113 & 3.218 & $0.758-13.662$ \\
\hline Cystoisospora spp. infection & Ref. & & & & & \\
\hline Constant $(f)$ & -6.10 & 1.008 & 36.59 & $<0.001$ & 0.002 & \\
\hline Constant (ts) & -5.59 & 1.011 & 30.58 & $<0.001$ & 0.004 & \\
\hline
\end{tabular}

Abbreviations: SE standard error, Cl confidence interval, Ref. reference category 
Table 8 Regression coefficients of the predictors used in Giardia spp. model for the full data set ( $f$ ) and the training sample (ts) used for the validation of the model

\begin{tabular}{lllllll}
\hline & $\mathrm{B}^{\mathrm{a}}$ & $\mathrm{SE}$ & Wald & $P$ & Odds ratio & $95 \% \mathrm{Cl}$ for Exp(B) \\
\hline$<6$ months (f) & 1.55 & 0.612 & 6.43 & 0.011 & 4.721 & $1.423-15.664$ \\
$<6$ months (ts) & 1.35 & 0.680 & 3.93 & 0.048 & 3.844 & $1.014-14.566$ \\
$>6$ months & Ref. & & & & & $0.058-0.327$ \\
No Ancylostomatidae infection (f) & -1.98 & 0.442 & 20.19 & $<0.001$ & 0.138 & $0.095-0.779$ \\
No Ancylostomatidae infection (ts) & -1.30 & 0.536 & 5.89 & 0.015 & 0.273 & \\
Ancylostomatidae infection & Ref. & & & & \\
Constant (f) & -2.59 & 0.288 & 81.01 & $<0.001$ & 0.075 & 0.046 \\
Constant (ts) & -3.08 & 0.418 & 54.26 & $<0.001$ & & \\
\hline
\end{tabular}

Abbreviations: SE standard error, Cl confidence interval, Ref. reference category

${ }^{\mathrm{a}}$ Regression coefficient

and thus provide prevalence estimates that can be considered reliable and generalizable.

Overall, the prevalence of feline parasitism in Greece with at least one parasite was $50.7 \%$ (583/1150 cats). Furthermore, the mean species richness (Menhinick's index) in the different regions of the country was between 0.41 and 0.69 parasites per cat (Table 2), while a remarkable difference was observed for the mean species richness between young and adult cats. Accordingly, high levels of feline gastrointestinal parasitism have been recorded in recent large-scale multicentric studies conducted in Europe $[11,12]$. In the Mediterranean region, studies report similar findings, e.g. 28.0\% in Spain [20], 35.0\% in Italy [21] and $35.7 \%$ in Cyprus [22]. In two small-scale regional surveys in Greece, high levels of feline gastrointestinal endoparasitism have been previously documented, which is in agreement with our findings. Particularly, the occurrence of infection in four islands and Athens was 46.7\%, whereas in Crete was $38.1 \%$ [14, 16]. The most frequently identified parasites in the studied cat population were T. cati, followed by Cystoisospora spp., Ancylostomatidae, A. abstrusus and Giardia spp. These findings are consistent with those reported in several other European countries [21].

Among protozoan parasites, the most commonly identified was Cystoisospora spp. (16.4\%, $n=189$ cats). Infections with Cystoisospora felis and Cystoisospora rivolta were documented as Cystoisospora spp., although they can be discriminated using morphological criteria [23]. The study of coccidia in cats in Greece needs further evaluation in the future due to the different pathogenicity of the two species. These parasites may destroy the lining of the intestine and cause mild to severe diarrhoea as well as vomiting and/or decreased appetite [24, 25]. Data about Cystoisospora spp. prevalence in Europe have been reported for owned cats in many countries, such as Romania (8.9\%) [26], northern Germany (7.5\%) [27], Portugal (5.0\%) [28], Italy (up to 4.5\%) [21] and the UK (3.0\%) [29], while in stray cats prevalence reaches up to $46.3 \%$ of the examined population
[30]. The prevalence found in our study (16.4\%) was much higher than in previous studies carried out in Greece, i.e. from 6.7 to $9.5 \%[12,14,16]$. This is probably due to the inclusion in the present study of a significantly higher number of samples originating from all parts of the country and hence a sharpened view of this infection was demonstrated, contrary to the regional coverage of the other studies. The high prevalence of Cystoisospora spp. in the present research implies that coccidia are more likely to pose a threat to cats than previously thought in Greece [12, 14, 16].

Relatively uncommon protozoan parasites found in our study were Giardia spp. (2.3\%; $n=26$ cats). Other surveys in Europe employing microscopy have recorded similar prevalences [31]. It should be noted that conventional microscopy is less sensitive for the detection of Giardia spp. cysts than other methods, such as immunological and molecular techniques. A meta-analysis demonstrated that the pooled Giardia spp. prevalence in feline faeces worldwide is $12.0 \%$, when such techniques are applied [31]. Hence, the actual prevalence of this protozoon may be higher in Greece than the estimated herein. Indeed, an increased prevalence (20.5\%) of giardiosis has been recorded in Crete in a study employing an immunofluorescence assay [16]. Giardia spp. may induce a range of signs, including diarrhoea, vomiting and anorexia, although many cats remain asymptomatic [29, 32]. It is worth noting that a recent study employing Ion Torrent GM sequencing reported that cats infected with Giardia spp. have a different faecal microbiome structure and composition than non-infected ones, suggesting an indirect effect of these protozoans in the metabolism of the upper gastrointestinal tract [33]. It should be highlighted that zoonotic strains have been documented [34], but it is unclear whether close contact with infected cats poses a real risk of infection to owners and shelter staff [32].

The zoonotic protozoan Toxoplasma gondii was not detected in the present study [35]. Diagnosis of toxoplasmosis in feline population by microscopy is difficult owing to the short shedding period of this parasite [36]. 
In addition, its specificity is questionable due to the similar appearance of other Apicomplexa parasites. Toxoplasma gondii infections are commonly identified by immunological and molecular techniques, which display higher sensitivity [37]. Serological data regarding feline toxoplasmosis in Greece are scarce and thus the actual presence of this parasitism in Greece is presumably underestimated. Finally, Tritrichomonas foetus was not detected in the present study. This protozoan is rarely detected by coprological examination and its presence has been confirmed by molecular methods in Greece with a prevalence of $20.0 \%$ [38].

According to our results, $T$. cati was the most prevalent helminth in cats in Greece. The characteristic dark-brown coloured eggs with thick-pitted shells were identified in $24.2 \%$ ( $n=278$ cats) of the examined faecal samples [39]. Toxocara cati has a direct life-cycle and its eggs can resist adverse climatic conditions and remain infective for years $[39,40]$. Moreover, T. cati infection arises in kittens due to lactogenic larval transmission $[39,41]$ while it can also be transmitted through the ingestion of infected paratenic hosts [42]. This particular biology and ecology favours the occurrence of this parasite amongst susceptible hosts and accounts for its cosmopolitan distribution [12, 42]. Toxocara cati is one of the most prevalent gastrointestinal parasites of cats globally [11]. Similarly to our study, other authors also point out the high proportion of parasitism by this ubiquitous nematode, especially in kittens $[8,20]$. In Europe, the infection rates range between $7.2-83.3 \%$ in cats [12, 16, 43]. Accordingly, the high level of infection with $T$. cati $(24.0 \%)$ was verified in two studies conducted mainly in insular Greece and in Athens $[14,16]$. The high prevalence of $T$. cati implies the necessity of effective deworming treatments for animals, particularly given the zoonotic potential of this nematode [10].

Toxocara cati eggs are dispersed via the animal's faeces in the environment and mature in soil. When people accidentally ingest the infective eggs, larvae hatch and migrate causing larva migrans syndromes, i.e. "visceral larva migrans" (VLM) and "ocular larva migrans" (OLM), with a wide range of presenting features [40, 42, 44]. It is assumed that $T$. cati may play a greater role in these larval syndromes than appraised and its zoonotic potential should not be underestimated [10, 45]. Studies have indicated that it is associated with both VLM and OLM, particularly in terms of causing permanent liver disorders and ocular lesions [42]. Human toxocarosis has been reported between the most frequently identified zoonoses worldwide [46]. Consequently, the high level of infection with $T$. cati detected in the present study should be considered, as it can have a major public health impact. Moreover, in order to restrain possible zoonotic transmission, the establishment of an informed cat owner population is pivotal [42, 44]. Up-to-date, published data regarding human toxocarosis in Greece is scarce and limited only to some sporadic cases [47-49]. Regarding felines, it is also speculated that $T$. cati infection has an effect on gut microbiota richness and diversity, most likely attributed to the immune-modulatory properties of this ascarid. Indeed, a recent study using cat faeces from Greece, positive and negative for T. cati eggs, demonstrated that bacteria belonging to the order Lactobacillales, the family Enterococcaceae and the genera Enterococcus and Dorea were more abundant in the infected samples, suggesting that certain differences in the composition of the gut microbiota of $T$. cati-positive $v s T$. cati-negative cats could be present [5].

Other nematodes detected in relatively high percentage were the soil-transmitted Ancylostomatidae (16.2\%; $n=186)$. Hookworms usually establish subclinical infections; however, they have an impact on feline health causing retarded growth and failure to thrive. Nevertheless, when heavy parasitism occurs, severe clinical signs, i.e. haemorrhagic enteritis and anaemia, due to the bloodfeeding behavior of these nematodes and the resulting ulcerations on the mucosa of the small intestine, manifest [50]. The diverse modes of transmission coupled with the well-documented zoonotic implications of these parasites highlight the importance of our findings [51]. The prevalence of hookworms in the present study was one of the highest recorded among European countries [52]. Although Beugnet et al. [11] recorded 1.4\% prevalence for felid hookworms in a multicentric study across Europe, other researchers demonstrated higher infection percentages, e.g. 10.1\% in Romania [26], 11.1\% in Hungary [53] and, surprisingly, 44.4\% in Albania [43]. In Greece, hookworm infections were found with prevalences of up to $6.8 \%$ in different regional surveys $[14,16]$.

Regarding parasitism of the respiratory tract by helminths, A. abstrusus was identified in 40 cats (3.5\%), while eggs of $C$. aerophila and larvae of $T$. brevior were detected in $8(0.7 \%)$ and $2(0.1 \%)$ cats, respectively. Similarly to our study, $A$. abstrusus was the most frequently diagnosed feline lungworm in Europe, a fact attributed to its broad host range $[11,12]$. The estimates of $A$. abstrusus infection may be influenced by the employment of diverse diagnostic methods. It should be indicated that when the Baermann technique is applied, higher prevalence estimates are recorded [52]. Indeed, according to recently conducted research, where the Baermann method was used, markedly higher infection rates reaching $16.7 \%$ in Romania [12], $17.4 \%$ in Portugal [54], 20.0\% in Italy [55, 56], 25.0\% in Hungary [12] and $35.8 \%$ in Bulgaria [12] have been reported, thus suggesting that these parts of Europe consist of enzootic areas. Accordingly, the occurrence of felid metastrongylids in recent surveys carried out with limited cat populations in Greece was up to $11.0 \%[12,15]$. Consequently, the actual infection with 
A. abstrusus in Greece is presumably much higher than the one reported in our study. Capillaria aerophila, yet with a not entirely clarified biology, has been reported occasionally as a cause of human pulmonary capillariosis [55]. The prevalence of C. aerophila observed in this study was lower than the reported prevalence in Italy, which ranges between $1.0-5.0 \%$ [21]. As in the case of A. abstrusus, the prevalence detected for Troglostrongylus brevior in the present study was lower than those reported in other countries of southern Europe [12, 57, 58] and in certain districts of Greece [15], estimated using the Baermann method.

The other ascarid infecting cats, Toxascaris leonina, was detected in $0.1 \%$ ( $n=2$ cats) of the samples. Our findings are in accordance to other studies from Europe where the prevalence estimate of this nematode was considerably low $(0.1-1.7 \%)$ [11, 20, 21, 52]. However, in some sporadic studies, contrary to our data, the percentages of infection were 7.2 [53] and 8.0\% [14].

Tapeworms belonging to the species Joyeuxiella pasqualei $(1.2 \%, n=14$ cats) and D. caninum $(0.2 \%, n=3$ cats) were found at a low prevalence. In Greece, Diakou et al. [14] documented $2.0 \%$ prevalence for $D$. caninum. However, there is a considerable intermittent excretion of cestode eggs and proglottids in faeces [2]. These helminths can cause non-specific clinical symptoms from the digestive tract, while the presence of proglottids in the perianal region or in the pet's environment is aesthetically unpleasant $[10,59]$.

Recognition of possible risk factors provides valuable clues for the prevention and the implementation of targeted antiparasitic treatments [60]. Primarily, Cystoisospora spp. and Giardia spp. infections were more common in young animals, being more likely (3.2 and 4.7 times, respectively) to shed oocysts or cysts to the environment than adults [61]. Young animals are more prone to protozoan infections due to an immature immune system. Infected kittens are not able to generate a sufficient immune response and consequently develop more severe clinical signs than older cats [24]. Interestingly, it has been demonstrated that Cystoisospora spp. prevalence drops to zero as age progresses, but increases steadily again when the cats are over 17 years-old [62].

In the same frame, Ancylostomatidae prevalence appeared to be significantly higher in stray than in household cats. This result is consistent with other surveys on stray or feral cats in Europe, where the reported prevalence rates of hookworms were $7.2 \%$ in Italy [63], 19.1\% in Portugal [30] and up to $47.0 \%$ in Spain [64]. It is worth noting that a study in Majorca revealed 91.0\% prevalence for Ancylostoma tubaeforme in feral cats [13], which was attributed to the warm and wet climate of this island, favouring the survival of hookworm larvae [65]. Likewise, infection with Cystoisospora spp. was more common in stray cats. Cystoisosporosis is more common in shelters as it has been previously reported [66]. The overall prevalence of these protozoans in stray or feral cats in selected studies conducted in Europe was from 11.8\% in Poland [67] and 19.3\% in the Netherlands [68] up to $46.3 \%$ in Portugal [30]. Due to the parasite's mode of transmission, clinical coccidiosis can be a pervasive problem in shelter environments, presumably due to crowded conditions with poor sanitation and hygiene. Such conditions favour the occurrence of parasitic infections, which are transmitted via the faecal oral route $[66,69,70]$. Additionally overcrowding enhances parasitism through immune suppression [71]. Other factors corroborating parasitism in multiple-cat households and catteries are the lack of effective antiparasitic treatment and the fact that young animals are not separated from adult ones $[30,52]$.

When infected, these free-ranging cats circulate on streets and can contaminate the environment with parasitic elements, thus representing a potential threat to other companion animals and people sharing the same habitat [30]. It is important to note that in Greece, there is a large population of stray cats living in colonies, even in the most visited touristic sites such as islands and archeological places. Furthermore, an increase in pet travel within continental Europe has been recorded due to the removal of border controls under the Schengen Treaty and implementation of the PETS Travel Scheme in the UK. Consequently, dogs and cats travelling to Greece for holidays may be at increased risk of acquiring infections. Cats imported from enzootic regions for specific parasites, e.g. the adoption of a Greek stray, should be promptly visited by a veterinarian and treated with an appropriate anthelmintic [10].

Infection with the cat lungworm, $A$. abstrusus, was strongly associated with animals living outdoors. Regarding A. abstrusus, Traversa et al. [72] also found that 38 out of the 40 infected cats had outdoor access, which was estimated as significant after multivariate analysis. In the same frame, Diakou et al. [22] pointed out that all cats infected with $A$. abstrusus in a study in Cyprus had an outdoor lifestyle. This is in accordance with the mode of transmission of this parasite, which utilizes terrestrial gastropods as obligatory intermediate hosts and also a wide range of vertebrates (rodents, lizards, frogs), which in sequence are common preys of cats and serve as paratenic hosts [73]. Likewise, $T$. cati infections were more common in animals living outdoors. In our study, the risk of being T. catipositive was 2.7 times higher for cats with frequent outdoor access compared to those which remained indoors. Similar findings have been demonstrated in other studies $[11,13,26,30,52,70]$. This discrepancy probably reflects differences in feed quality and anthelmintic treatments [13]. Indeed, cats living indoors attract more attention and receive better preventive treatments than the ones living 
outdoors. Moreover, it may suggest that persistence of $T$. cati eggs in the outdoor environment as well as paratenic hosts play a crucial role in the transmission of this ascarid [18].

Our results confirm concurrent profile of infections in the studied feline population and suggest that the presence of certain parasites increases the infection potential with others. In details, animals infected with Ancylostomatidae were most likely to be infected with Giardia spp. and vice versa. In the same context, cats free of Cystoisospora spp. were at most risk of $A$. abstrusus infection. On the other hand, cats free of $A$. abstrusus were more likely to be infected with Cystoisospora spp. Finally, cats infected with Cystoisospora spp. were at most risk of being co-infected with $T$. cati. One possible explanation for these outcomes relies to the age, young cats being more infected with coccidia and Toxocara than Aelurostrongylus. Another explanation could be related to the immune responses. In immunological studies conducted in mice and humans, concerning the interplay of helminths and protozoa $[74,75]$, it has been proposed that the immunemodulatory abilities of helminths, such as the $\mathrm{Th}_{2}$ strong polarization and the provoked generalized immunosuppression, abate the generally antagonistic $\mathrm{Th}_{1}$-dependent, cell-mediated immune response against protozoans [76, 77]. Indeed, it has been demonstrated that the strong $\mathrm{Th}_{2}$ polarization during a helminth (Trichinella spiralis) infection in mice promotes infection due to Giardia spp. [78]. This trend of strong immunemodulatory effect on the host has also been attributed to chronic hookworm infections [79]. This interaction implies that certain conditions in the gastrointestinal tract serve as predisposing factors for these parasitoses. Since microbiome, mucosal and systemic immunity are closely linked [80], it is speculated that helminth-associated microbiome further polarizes protozoan infections [33]. Consequently, nematodoses in cats have to be viewed in the context of concurrent protozooses.

Concerning gender, the likelihood of Cystoisospora spp. infection was found 1.4 times higher for male cats, while a 1.3 higher probability for $T$. cati infection was recorded for female cats, although not statistically significant $(P=0.08)$. Possible pregnancy in female cats may have an immunosuppressive effect [81], and thus influence gastrointestinal parasite shedding rates. In addition, changes of being parasitized by T.cati become greater in females owing their more affiliative behaviour (allorub, allogroom, social sniff and amicable approach) [82].

\section{Conclusions}

In conclusion, this study depicts that gastrointestinal parasites are a common finding in cats in Greece. The endoparasitic fauna detected was diversified, which indicates that people in Greece are at risk of exposure to some potentially zoonotic parasitic genera. The presence of felid parasitism depends on the level of awareness among owners, and thus it is recommended to educate cat owners and increase perception of the risks involved. Additionally, the findings reported above emphasize the importance of conducting routine and repeated faecal examinations, even in the well-cared pet population, and administering accurate preventive measures and treatments. Regarding stray cats, it is essential to apply appropriate hygiene in shelters and include antiparasitic control strategies in stray cat neutering campaigns. This study contributes to an improved understanding of the epizootiological patterns of feline parasites in Greece. Future fields of research may comprise the employment of sensitive serological or molecular tools and the further development of prediction models based on the integration of specific risk factors.

\section{Additional file}

Additional file 1: Table S1. Information regarding origin, gender, ownership status, living conditions, age and infection status for the various detected parasite taxa for each sampled animal. Table S2. Coding for data in Table S1. Table S3. Number and prevalence (\%) of infected (per parasite taxon) cats in all sampled regions of Greece. (XLSX 78 kb)

\section{Abbreviations}

OLM: ocular larva migrans; VLM: viscelar larva migrans

\section{Acknowledgements}

Not applicable.

\section{Funding}

The study was partially funded by Merial Animal Health, France (cost of consumables and publication fees).

Availability of data and materials

The dataset generated and analyzed during the current study is included within the article and its additional file.

\section{Authors' contributions}

IS participated in study design, parasitological methods and preparation of the manuscript. GAl participated in study design, statistical analyses and preparation of the manuscript. KA and AA participated in parasitological methods. FB and EP participated in study design and critical review of the manuscript. All authors read and approved the final manuscript.

\section{Ethics approval and consent to participate}

The study was conducted in compliance with the national animal welfare regulations. The applied diagnostic veterinary procedures are not within the context of relevant EU legislation for animal experimentations (Directive 86/609/EC) and may be performed in order to diagnose animal diseases and improve animal welfare. No suffering was caused during sample collection. Consent was obtained from owners or registered veterinarians (private, public or municipality, depending on the case).

\section{Consent for publication}

Not applicable.

\section{Competing interests}

FB is an employee of Boehringer Ingelheim, but the survey was purely epizootiological without any product use. The other authors declare that they have no competing interests. 


\section{Publisher's Note}

Springer Nature remains neutral with regard to jurisdictional claims in published maps and institutional affiliations.

\section{Author details}

'Laboratory of Parasitology and Parasitic Diseases, School of Veterinary Medicine, Faculty of Health Sciences, Aristotle University of Thessaloniki, PO Box: 393, GR 54124 Thessaloniki, Greece. ${ }^{2}$ Veterinary Research Institute of Thessaloniki, ELGO-Demeter, GR 57001 Thermi, Thessaloniki, Greece. ${ }^{3}$ Boehringer Ingelheim, 29 Avenue Tony Garnier, 69007 Lyon, France.

\section{Received: 1 December 2017 Accepted: 25 March 2018} Published online: 04 April 2018

\section{References}

1. Friedmann $\mathrm{E}$, Son $\mathrm{H}$. The human-companion animal bond: how humans benefit. Vet Clin North Am Small Anim Pract. 2009;39:293-326.

2. Dantas-Torres F, Otranto D. Dogs, cats, parasites and humans in Brazil: opening the black box. Parasit Vectors. 2014;7:22.

3. Traversa D. Pet roundworms and hookworms: a continuing need for global worming. Parasit Vectors. 2012;5:91-110.

4. Sherding RG, Johnson SE. Diseases of the intestine. In: Birchard SJ, Sherding RG, editors. Saunders manual of small animal practice. St. Louis: Mendor; 2008. p. 702-38.

5. Duarte AM, Jenkins TP, Latrofa MS, Giannelli A, Papadopoulos E, de Carvalho LM, et al. Helminth infections and gut microbiota - a feline perspective. Parasit Vectors. 2016;9:625.

6. Overgaauw PAM, van Knapen F. Veterinary and public health aspects of Toxocara spp. Vet Parasitol. 2013;193:398-403.

7. Raether W, Hanel H. Epidemiology, clinical manifestations and diagnosis of zoonotic cestode infections: an update. Parasitol Res. 2003;91:412-38.

8. Deplazes P, van Knapen F, Schweiger A, Overgaauw PA. Role of pet dogs and cats in the transmission of helminthic zoonoses in Europe, with a focus on echinococcosis and toxocarosis. Vet Parasitol. 2011;182:41-53.

9. Baneth G, Thamsborg SM, Otranto D, Guillot J, Blaga R, Deplazes P, et al. Major parasitic zoonoses associated with dogs and cats in Europe. J Comp Pathol. 2016;155(Suppl. 1):54-74.

10. ESCCAP. GL1: Worm control in dogs and cats. In: ESCCAP Guidelines. ESCCAP. 2017. http://www.esccap.org/page/GL1+Worm+Control+in+Dogs+and+Cats/ 25/\#.WhFLHrjzJv8. Accessed July 2017.

11. Beugnet F, Bourdeau P, Chalvet-Monfray K, Cozma V, Farkas R, Guillot J, et al. Parasites of domestic owned cats in Europe: co-infestations and risk factors. Parasit Vectors. 2014;7:291.

12. Giannelli A, Capelli G, Joachim A, Hinney B, Losson B, Kirkova Z, et al. Lungworms and gastrointestinal parasites of domestic cats: a European perspective. Int J Parasitol. 2017:47:517-28.

13. Millan J, Casanova JC. High prevalence of helminth parasites in feral cats in Majorca Island (Spain). Parasitol Res. 2009;106:183-8.

14. Diakou A, Di Cesare A, Accettura PM, Barros L, lorio R, Paoletti B, et al. Intestinal parasites and vector-borne pathogens in stray and free-roaming cats living in continental and insular Greece. PLoS Negl Trop Dis. 2017;11: e0005335.

15. Diakou A, Di Cesare A, Barros LA, Morelli S, Halos L, Beugnet F, et al. Occurrence of A. abstrusus and Troglostrongylus brevior in domestic cats in Greece. Parasit Vectors. 2015;8:590.

16. Kostopoulou D, Claerebout E, Arvanitis D, Ligda P, Voutzourakis N, Casaert S, et al. Abundance, zoonotic potential and risk factors of intestinal parasitism amongst dog and cat populations: The scenario of Crete, Greece. Parasit Vectors. 2017;10:43.

17. Faust EC, D'Antonio JS, Odom V, Miller MJ, Peres C, Sawitz W, et al. A critical study of clinical laboratory techniques for the diagnosis of protozoan cysts and helminth eggs in feces. Am J Trop Med Hyg. 1938;18:169-83.

18. Taylor MA, Coop RL, Wall RL. Veterinary Parasitology. 3rd ed. Oxford: Blackwell Publishing Ltd; 2007.

19. Beugnet F, Halos L. Parasitoses and vector borne diseases of cats. 2nd ed. Lyon: Merial; 2015.

20. Miro G, Montoya A, Jimenez S, Frisuelos C, Mateo M, Fuentes I. Prevalence of antibodies to Toxoplasma gondii and intestinal parasites in stray, farm and household cats in Spain. Vet Parasitol. 2004;126:249-55.

21. Riggio F, Mannella R, Ariti G, Perruccia S. Intestinal and lung parasites in owned dogs and cats from central Italy. Vet Parasitol. 2013;193:78-84.
22. Diakou A, Sofroniou D, Di Cesare A, Kokkinos P, Traversa D. Occurrence and zoonotic potential of endoparasites in cats of Cyprus and a new distribution area for Troglostrongylus brevior. Parasitol Res. 2017;116:3429-35.

23. Lindsay DS, Dubey JP, Blagburn BL. Biology of Isospora spp. from humans, nonhuman primates, and domestic animals. Clin Microbiol Rev. 1997;10:19-34.

24. ESCCAP. GL6: Control of intestinal protozoa in dogs and cats. In: ESCCAP Guidelines. ESCCAP. 2011. http://www.esccap.org/page/GL6+Control+of+Intestinal +Protozoa+in+Dogs+and+Cats/30/\#.WhFJ87jzJv8. Accessed August 2011.

25. Greene CE. Infectious diseases of the dog and cat. 4th ed. St. Liouis: Elsevier Sauders; 2013.

26. Mircean V, Titilincu A, Vasile C. Prevalence of endoparasites in household cat (Felis catus) populations from Transylvania (Romania) and association with risk factors. Vet Parasitol. 2010;171:163-6.

27. Barutzki D, Schaper R. Results of parasitological examinations of faecal samples from cats and dogs in Germany between 2003 and 2010. Parasitol Res. 2011;109(Suppl. 1):45-60.

28. Ferreira FS, Pereira-Baltasar P, Parreira R, Padre L, Vilhen M, Tavira LT, et al. Intestinal parasites in dogs and cats from the district of Evora, Portugal. Vet Parasitol. 2011;179:242-5.

29. Tysnes KR, Skancke E, Robertson L. Subclinical Giardia in dogs: a veterinary conundrum relevant to human infection. Trends Parasitol. 2014;30:520-7.

30. Waap H, Gomes J, Nunes T. Parasite communities in stray cat populations from Lisbon, Portugal. J Helminthol. 2014;88:389-95.

31. Bouzid M, Halai K, Jeffreys D, Hunter PR. The prevalence of Giardia infection in dogs and cats, a systematic review and meta-analysis of prevalence studies from stool samples. Vet Parasitol. 2015;207:181-202.

32. Ballweber LR, Xiao L, Bowman DD, Kahn G, Cama VA. Giardiasis in dogs and cats: update on epidemiology and public health significance. Trends Parasitol. 2010;26:180-9.

33. Slapeta J, Dowd CE, Alanazi AD, Westman ME, Brown GM. Differences in the faecal microbiome of non-diarrhoeic clinically healthy dogs and cats associated with Giardia duodenalis infection: impact of hookworms and coccidian. Int J Parasitol. 2015;45:585-94.

34. Thompson RA, Palmer CS, O'Handley R. The public health and clinical significance of Giardia and Cryptosporidium in domestic animals. Vet J. 2008;177:18-25.

35. Cook AJC, Gilbert RE, Buffolano W, Zufferey J, Petersen E, Jenum PA, et al. Sources of Toxoplasma infection in pregnant women: European multicenter case-control study. BMJ. 2010;321:142-7.

36. Dubey JP. Toxoplasmosis of animals and humans. 2nd ed. Boca Raton: CRC Press; 2010.

37. Wyrosdick HM, Schaefer JJ. Toxoplasma gondii: history and diagnostic test development. Anim Health Res Rev. 2015;16:150-62.

38. Xenoulis PG, Saridomichelakis MN, Read SA, Suchodolski JS, Steiner JM. Detection of Tritrichomonas foetus in cats in Greece. J Feline Med Surg. 2010;12:831-3.

39. Parsons JC. Ascarid infections of cats and dogs. Vet Clin North Am Small Anim Pract. 1987;17:1303-7.

40. Despommier D. Toxocariasis: clinical aspects, epidemiology, medical ecology, and molecular aspects. Clin Microbiol Rev. 2003;16:265-72.

41. Coati N, Schnieder T, Epe C. Vertical transmission of Toxocara cati Schrank, 1788 (Anisakidae) in the cat. Parasitol Res. 2004;92:142-6.

42. Lee CY, Schantz PM, Kazacos KR, Montgomery SP, Bowman DD. Epidemiologic and zoonotic aspects of ascarid infections in dogs and cats. Trends Parasitol. 2010;26:155-61.

43. Knaus M, Kusi I, Rapti D, Xhaxhiu D, Winter R, Visser M, et al. Endoparasites of cats from the Tirana area and the first report on Aelurostrongylus abstrusus (Railliet, 1898) in Albania. Wien Klin Wochenschr. 2011;123(Suppl 1):31-5.

44. Smith H, Holland C, Taylor M, Magnaval MF, Schantz P, Maizels R. How common is human toxocariasis? Towards standardizing our knowledge. Trends Parasitol. 2009;25:182-8.

45. Fisher M. Toxocara cati: an underestimated zoonotic agent. Trends Parasitol. 2003;19:167-70.

46. Rubinsky-Elefant G, Hirata CE, Yamamoto JH, Ferreira MU. Human toxocariasis: diagnosis, worldwide seroprevalences and clinical expression of the systemic and ocular forms. Ann Trop Med Parasitol. 2010;104:3-23.

47. Xinou E, Lefkopoulos A, Gelagoti M, Drevelegas A, Diakou A, Milonas I, et al. $C T$ and MR imaging findings in cerebral toxocaral disease. AJNR Am J Neuroradiol. 2003;24:714-8.

48. Haralambidou S, Vlachaki E, loannidou E, Milioni V, Haralambidis S, Klonizakis I. Pulmonary and myocardial manifestations due to Toxocara canis infection. Eur J Intern Med. 2005;16:601-2. 
49. Theodoridis I, Frydas S, Papazahariadou M, Hatzistilianou M, AdamamaMoraitou KK, Di Gioacchino M, et al. Toxocarosis as zoonosis. A review of literature and the prevalence of Toxocara canis antibodies in 511 serum samples. Int J Immunopathol Pharmacol. 2001;14:17-23.

50. Kalkofen UP. Hookworms of dogs and cats. Vet Clin North Am Small Anim Pract. 1987:17:1341-54.

51. Bowman DD, Montgomery SP, Zajac AM, Eberhard ML, Kazacos KR. Hookworms of dogs and cats as agents of cutaneous larva migrans. Trends Parasitol. 2010;26:162-7.

52. Becker AC, Rohen M, Epe C, Schnieder T. Prevalence of endoparasites in stray and fostered dogs and cats in northern Germany. Parasitol Res. 2012; 111:849-57.

53. Capari B, Hamel D, Visser M, Winter R, Pfister K, Rehbein S. Parasitic infections of domestic cats, Felis catus, in western Hungary. Vet Parasitol. 2013;192:33-42

54. Payo-Puente $\mathrm{P}$, Botelho-Dinis M, Carvaja Uruen AM, Payo-Puente M, Gonzalo-Orden JM, Rojo-Vazquez FA. Prevalence study of the lungworm Aelurostrongylus abstrusus in stray cats of Portugal. J Fel Med Surg. 2008;10:242-6.

55. Traversa D, Di Cesare A, Conboy G. Canine and feline cardiopulmonary parasitic nematodes in Europe: emerging and underestimated. Parasit Vectors. 2010;3:62

56. Di Cesare A, Castagna G, Meloni S, Milillo P, Latrofa S, Otranto D. Canine and feline infections by cardiopulmonary in central and southern Italy. Parasitol Res. 2011;109:87-96.

57. Brianti E, Giannetto S, Dantas-Torres F, Otranto D. Lungworms of the genus Troglostrongylus (Strongylida: Crenosomatidae): neglected parasites for domestic cats. Vet Parasitol. 2014;202:104-12.

58. Di Cesare A, Di Francesco G, Frangipane di Regalbono A, Eleni C, De Liberato C, Marruchella G, et al. Retrospective study on the occurrence of the feline lungworms Aelurostrongylus abstrusus and Troglostrongylus spp. in endemic areas of Italy. Vet J. 2015:203:233-8.

59. Bowman DD, Hendrix CM, Lindsay DS, Barr SC. Feline clinical parasitology. lowa: Blackwell Science; 2002

60. Fontanarrosa MF, Vezzani D, Basabe J, Eiras DF. An epidemiological study of gastrointestinal parasites of dogs from southern Greater Buenos Aires (Argentina): Age, gender, breed, mixed infections, and seasonal and spatial patterns. Vet Parasitol. 2006;136:283-95.

61. Lappin MR. Update on the diagnosis and management of Isospora spp. infections in dogs and cats. Top Companion Anim Med. 2010;25:133-5.

62. Gates MC, Nolan TJ. Endoparasite prevalence and recurrence across different age groups of dogs and cats. Vet Parasitol. 2009;166:153-8.

63. Spada E, Proverbio D, Della Pepa A, Domenichini G, Bagnagatti De Giorgi G, Traldi G, et al. Prevalence of faecal-borne parasites in colony stray cats in northern Italy. J Feline Med Surg. 2013;15:672-7.

64. Millan J, Casanova JC. Helminth parasites of the endangered Iberian lynx (Lynx pardinus) and sympatric carnivores. J Helminthol. 2007;81:377-80

65. Matthews BE. The influence of temperature and osmotic stress on the development and eclosion of hookworm eggs. J Helminthol. 1985;59:217-24.

66. Villeneuve A, Polley L, Jenkins E, Schurer J, Gilleard J, Kutz S, et al. Parasite prevalence in fecal samples from shelter dogs and cats across the Canadian provinces. Parasit Vectors. 2015;8:281.

67. Szwabe K, Blaszkowska J. Stray dogs and cats as potential sources of soil contamination with zoonotic parasites. Ann Agric Environ Med. 2017;24:39-43.

68. Robben SR, le Nobel WE, Dopfer D, Hendrikx WM, Boersema JH, Fransen F, et al. Infections with helminths and/or protozoa in cats in animals shelters in the Netherlands. Tijdschr Diergeneeskd. 2004;129:2-6.

69. Dubey JP, Lindsay DS, Lappin RL. Toxoplasmosis and other intestinal coccidial infections in cats and dogs. Vet Clin Small Anim. 2009;39:1009-34.

70. Takeuchi-Storm N, Mejer H, Al-Sabi MNS, Olsen CS, Thamsborg SM, Enemark HL. Gastrointestinal parasites of cats in Denmark assessed by necropsy and concentration McMaster technique. Vet Parasitol. 2015;214:327-32.

71. Day MJ. Immune system development in the dog and cat. J Comp Pathol. 2007;137(Suppl. 1):10-5.

72. Traversa D, Lia RP, lorio R, Boari A, Paradies P, Capelli G, et al. Diagnosis and risk factors of Aelurostrongylus abstrusus (Nematoda, Strongylida) infection in cats from Italy. Vet Parasitol. 2008;153:182-6.

73. Di Cesare A, Crisi PE, Di Giulio E, Veronesi F, di Regalbono AF, Talone T, et al Larval development of the feline lungworm Aelurostrongylus abstrusus in Helix aspersa. Parasitol Res. 2013;112:3101-8.
74. Hamm DM, Agossow A, Gantin RG, Kocherschneidt L, Banla Dietz K, Sloboslay PT. Co-infections with Schistosoma haematobium, Necator americanus, and Entamoeba histolytica/Entamoeba dispar in children: chemokine and cytokine responses and changes after antiparasite treatment. J Infect Dis. 2009;199:1583-91.

75. Hagel I, Cabrera M, Puccio F, Santaella C, Buvat E, Infante B, et al. Coinfection with Ascaris lumbricoides modulates protective immune responses against Giardia duodenalis in school Venezuelan rural children. Acta Trop. 2011;117: 189-95.

76. Fietta $P$, Delsante $G$. The effector T helper cell triade. Riv Biol-Biol Forum. 2009;102:61-74.

77. Ezenwa VO, Jolles AE. From host immunity to pathogen Invasion: the effects of helminth coinfection on the dynamics of microparasites. Integr Comp Biol. 2011;51:540-51.

78. von Allmen N, Christen S, Forster U, Gottstein B, Welle M, Muller N. Acute trichinellosis increases susceptibility to Giardia lamblia infection in the mouse model. Parasitology. 2006;133:139-49.

79. McSorley HJ, Loukas A. The immunology of human hookworm infections. Parasite Immunol. 2010;32:549-59.

80. Pflughoeft KJ, Versalovic J. Human microbiome in health and disease. Annu Rev Pathol. 2012;7:99-122.

81. Munoz-Suano A, Hamilton AB, Betz AG. Gimme shelter: the immune system during pregnancy. Immunol Rev. 2011;241:20-38.

82. Barry KJ, Crowell-Davis SL. Gender differences in the social behavior of the neutered indoor-only domestic cat. Appl Anim Behav Sci. 1999;64:193-211.

\section{Submit your next manuscript to BioMed Central and we will help you at every step:}

- We accept pre-submission inquiries

- Our selector tool helps you to find the most relevant journal

- We provide round the clock customer support

- Convenient online submission

- Thorough peer review

- Inclusion in PubMed and all major indexing services

- Maximum visibility for your research

Submit your manuscript at www.biomedcentral.com/submit 